\title{
NUMERICAL MODELLING OF CYCLIC PULL-OUT BEHAVIORS OF EMBEDDED PLATE ANCHORS IN SATURATED SOFT CLAY
}

\author{
Cun Hu \\ Institute of Mechanics, Chinese Academy of \\ Sciences \\ Beijing, China
}

\author{
Fu-ping Gao \\ Institute of Mechanics, Chinese Academy of \\ Sciences \\ Beijing, China
}

\begin{abstract}
As a foundation for deep-water floating offshore structures, the embedded plate anchor should withstand the complicated marine conditions involving the cyclic loads. The pull-out behaviors of the embedded plate anchor under cyclic loading must be considered whilst designing. This paper presents a numerical approach for assessing the cyclic pull-out behaviors of the embedded plate anchor based on a recently proposed anisotropic bounding surface plasticity model, which can capture the non-failure stable and degradation characteristics of saturated soft clay under cyclic loading with different stresslevels. The pull-out behaviors of the embedded plate anchor under both monotonic and cyclic loading are simulated and investigated. Effects of the mean value, the amplitude of the cyclic loading on the cyclic pull-out behaviors are analyzed. The results demonstrate that under different cyclic loading levels three typical types of the cyclic pull-out behaviors are obtained, i.e., the cyclic stable, the cyclic hypo-stable and the cyclic degradation.
\end{abstract}

\section{INTRODUCTION}

The embedded plate anchors such as the drag-in plate anchor, suction embedded plate anchor etc., are often deeply embedded in the seabed to keep their stability and functionality under the extremely harsh ocean environments. Inevitably, the low-frequency cyclic loads induced by winds and waves etc. will act on anchors and surrounding seabed soils [1]. Consequently, the complicated and evolving cyclic behaviors of seabed soils are likely to cause a major change on the pull-out capacity of the embedded plate anchors under the cyclic loading $[2,3]$.

The pull-out capacity of the embedded plate anchor subjected to cyclic loading is a complex interaction problem involving the seabed soil, water, the structure and the loading patterns. Moreover, capturing the complex but important cyclic behaviors of seabed soils often makes the constitutive models more lengthy and complicated [4]. Thus, the theoretical and numerical analyses on the cyclic pull-out behaviors of embedded plate anchors with an appropriate cyclic constitutive model of seabed soils still confront challenges.

Det Norshke Veritas (DNV) RP-E302 [2] recommended a computational method to evaluate the cyclic pull-out capacity of embedded plate anchor, which is based on the fundamental work on the cyclic response of gravity base foundations by Anderson et al. [5]. In their work, Anderson et al. assumed that the typical characteristics of soil elements on the potential failure surface can be depicted by the cyclic triaxial and direct simple shear tests. With the definition of the cyclic shear strength of the typical soil elements, by considering the problem as two-dimensional, postulating a potential failure surface, and fulfilling the limit equilibrium conditions, the cyclic bearing capacity of the gravity base or the embedded plate anchor can be achieved following the static limited equilibrium analysis.

Model tests on the cyclic behaviors of embedded plate anchors [6-9] have shown that there is a threshold value of cyclic loading below which the plate anchor will reach a stable state and the pull-out capacity would not decrease. While, if the loading level exceeds the threshold value, the plate anchor will reach failure due to large deformation and stiffness degradation of seabed soils. Obviously, the above-mentioned limited equilibrium method could not capture the above typical pull-out behaviors under different loading levels as well as the important responses during the cyclic loading such as the accumulation of the displacement and the evolvement of the stiffness.

In the present work, a new method for assessing the cyclic pull-out behaviors of the embedded plate anchor is presented based on a recently proposed bounding surface plasticity (BSP) model [10]. The BSP model could capture the cyclic behaviors of saturated clay under different cyclic stress levels. The method is firstly validated against the bearing behavior of a 
strip foundation on the saturated clay. Then, numerical simulations of cyclic loading tests on the embedded plate anchor with different combinations of the static mean loads and cyclic loads are conducted and systematically analyzed.

\section{FEM MODEL}

The finite element calculations were carried out using ABAQUS [11]. One type of drag-in plate anchor, e.g., the vertically loaded plate anchor (VLA) was chosen for the study. To simplify the problem, a two-dimensional finite element model was established, as illustrated in Fig. 1. The soil domain was set up $11 B$ by $11 B$, where $B$ is the width of the plate anchor. The dimensions of the plate anchor were $3 \mathrm{~m}$ in width and $0.2 \mathrm{~m}$ in thickness. VLA was regarded as a rigid body. The constitutive model of the soil is the anisotropic bounding surface plasticity (BSP) model established by Hu et al. [10].

\subsection{Anisotropic Bounding Surface Plasticity Theory}

\subsubsection{Framework Of The BSP Model}

In the anisotropic bounding surface plasticity (BSP) model used here, by extending the Masing's rule to the boundingsurface plasticity theory, the stress reversal point was taken as the generalised homological centre of the bounding surface. It is assumed that the bounding surface hardens isotropically around the discrete generalised homological center and has an initial inclination due to anisotropic consolidation of soils. Thereby, the characteristics of isotropic, kinematic and rotational hardening rules are included in the BSP model. Besides, a damage parameter related to the accumulated deviatoric plastic strain is incorporated into the form of the bounding surface, which is hence able to contract to model degradations in stiffness and strength of soils. The shape of the bounding surface is shown graphically in Fig. 2, depicting that the bounding-surface in the $p-q$ stress space is an elliptic, while in the deviatoric plane it follows the Mises criterion. In Fig. 2, the subscripts 0 and $m$ refer to the variables related with the first loading event and the subsequent loading event, respectively.

The associated flow and the radial mapping rules are adopted in the model. The main equations used in the mathematical formulation of the BSP model are given in Table 1. Details on the calibration of the model parameters can be seen in the paper [10]. The BSP model is encoded in the ABAQUS through a user-defined subroutine.

\subsubsection{Validation Of The BSP Model}

To investigate the capability of the BSP model to predict the foundation behavior on a saturated clay, numerical simulations on the monotonic and cyclic loading tests of a strip conducted by Das and Shin [12] has been performed. The tests were carried out on the soil samples of $22.9 \mathrm{~cm}$ wide, $91.5 \mathrm{~cm}$ long and $60.7 \mathrm{~cm}$ high and the size of footing was $7.61 \mathrm{~cm}$ wide, $22.9 \mathrm{~cm}$ long and $3.81 \mathrm{~cm}$ high. Note that the soil is under its own weight and an additional surcharge of $19 \mathrm{kPa}$, through which the shear strength of the clay varies with depth. For the cyclic test, the footing was subjected to a static load of 17.4
$\mathrm{kPa}$, which superimposed a cyclic load of $2.54 \mathrm{kPa}$. The soil property and model parameters used are given in Table 2.

Fig. 3 shows the comparison between the experimental data and the simulated load-settlement curve of the strip footing under the monotonic loading. Fig. 4 is the settlement accumulation with the number of loading cycles. It was observed that the simulation results of both the monotonic and cyclic loading tests are generally coincident with the experimental data. At the initial loading stage, the displacement accumulates rapidly followed by decline in the rate of accumulation with the number of cycles until almost zero. The cyclic load-settlement curve calculated by the model is demonstrated in Fig. 5, which shows the hysteresis loop is approximately closed at the stable state. It demonstrates that the numerical method based on the BSP model can be used for simulating the cyclic behavior of the foundation.

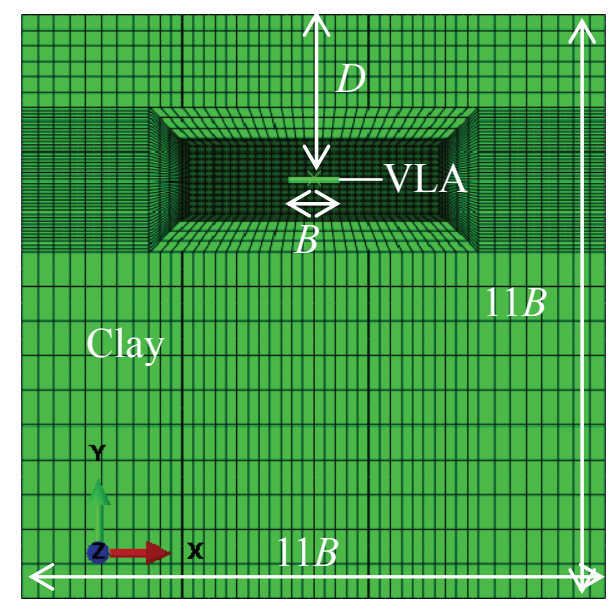

Fig. 1 FEM model for the pull-out behaviors of VLA

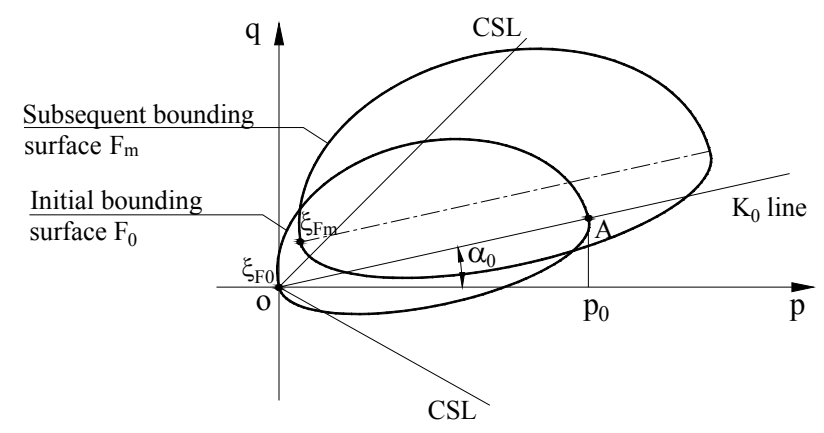

Fig. 2 Schematic of the bounding surface in the $p-q$ space

\subsection{Initial And Boundary Conditions}

In Fig. 1, the lateral boundaries of the soil are fixed in the $\mathrm{X}$ direction but are allowed to move in the $\mathrm{Y}$ direction, and the bottom boundary is locked in all directions. The interface condition of no detachment of the plate anchor from the soil was assumed. The plate anchor was tied to the soil elements, 
Table 1 Framework of the BSP model used in the present simulations (further details see Hu et al. [10] and Hu and Liu [4])

\begin{tabular}{|c|c|c|c|c|c|}
\hline \multicolumn{2}{|c|}{ Model composition } & Main Equations & Constants and explanations & \multicolumn{2}{|r|}{ Notes } \\
\hline \multicolumn{2}{|c|}{ Bounding-surface } & $F_{m}=\hat{p}^{2}-\hat{p} p_{c}+\frac{3}{2\left(M^{2}-\alpha^{2}\right)} \hat{\mathbf{s}}: \hat{\mathbf{s}}=0$ & $\begin{array}{l}M \text { is the slope of the } \\
\text { critical state line. }\end{array}$ & \multicolumn{2}{|c|}{$\begin{array}{l}\text { The bounding-surface in the } p-q \text { stress space is an } \\
\text { elliptic, and in the deviatoric plane following the } \\
\text { Mises criterion. }\end{array}$} \\
\hline \multirow[t]{3}{*}{$\begin{array}{l}\text { Hardening } \\
\text { rules }\end{array}$} & Isotropic & $\begin{array}{l}p_{c}=p_{0} \exp \left(\frac{1+e_{0}}{\lambda-\kappa} \varepsilon_{v}^{p}\right) H, H=\exp \left(-\beta \varepsilon_{A}\right) \\
\varepsilon_{A}=\sqrt{\frac{2}{3} \mathbf{e}^{p}: \mathbf{e}^{p}}\end{array}$ & $\begin{array}{l}e_{0} \text { is the initial void ratio; } \\
\lambda \text { and } \kappa \text { are the slopes of the } \\
\text { compression and swelling } \\
\text { lines in the } e-\ln p \text { space, } \\
\text { respectivley; } \beta \text { controls the } \\
\text { contraction of the bounding } \\
\text { surface. }\end{array}$ & \multicolumn{2}{|c|}{$\begin{array}{l}p_{c} \text { defines the isotropic hardening and determines } \\
\text { the size of the bounding surface, which depends } \\
\text { on the irreversible volumetric strain } \varepsilon_{v}^{p} \text { and the } \\
\text { damage parameter } H \text { related to the deviatoric } \\
\text { plastic strain } \mathbf{e}^{p} \text {. }\end{array}$} \\
\hline & Kinematic & $\xi^{(m+1)}=\xi^{(m)}+(\boldsymbol{\sigma}-\overline{\boldsymbol{\sigma}}) \quad$ if $\quad \overline{\mathbf{n}}_{n}: \boldsymbol{\sigma}_{n+1} \geq 0$ & & \multicolumn{2}{|c|}{$\begin{array}{l}\xi \text { denotes the endpoint of the bounding surface, } \\
\text { which evolves with the translating stress reversal } \\
\text { point. }\end{array}$} \\
\hline & Rotation & $\boldsymbol{\alpha}=\boldsymbol{\alpha}^{0}=\mathbf{s}^{0} / p_{0}$ & & \multicolumn{2}{|c|}{$\begin{array}{l}\alpha \text { defines the rotation of the bounding surface due } \\
\text { to anisotropic consolidation of soils. }\end{array}$} \\
\hline \multicolumn{2}{|c|}{ Mapping center } & $\mathbf{o}_{n+1}= \begin{cases}\mathbf{o}_{n} & \text { if } \overline{\mathbf{n}}_{n}: \boldsymbol{\sigma}_{n+1} \geq 0 \\
\boldsymbol{\sigma}_{n} & \text { if } \overline{\mathbf{n}}_{n}: \boldsymbol{\sigma}_{n+1}<0\end{cases}$ & & \multicolumn{2}{|c|}{$\begin{array}{l}\text { The stress reversal point is taken as the mapping } \\
\text { center } \mathbf{o} \text { in the radial mapping rule. }\end{array}$} \\
\hline & city & $\dot{\mathbf{e}}^{e}=\frac{\dot{\mathbf{s}}}{2 G}, \quad \dot{\varepsilon}_{v}^{e}=\frac{\dot{p}}{K}, G=\frac{3(1-2 v)}{2(1+v)} K$ & $\begin{array}{l}G, v \text { are the shear modulus } \\
\text { and the Poisson's ratio, } \\
\text { respectivley }\end{array}$ & & \\
\hline \multicolumn{2}{|c|}{ Plasticity modulus } & $K_{p}=\overline{K_{p}}+\rho\left(\bar{p}, \overline{\mathbf{s}}, \varepsilon_{v}^{p}, \mathbf{e}^{p}\right)(b-1)^{\gamma}$ & $\begin{array}{l}\gamma \text { is a monotonic loading } \\
\text { constant, of which the } \\
\text { typical value lies in the } \\
\text { range of } 1-2 ; \eta \text { and } \varsigma_{r} \text { are } \\
\text { the parameters for unloading } \\
\text { and reloading, which can be } \\
\text { induced by the dynamic } \\
\text { shear modulus and the } \\
\text { damping ratio. }\end{array}$ & $\rho\left(\bar{p}, \overline{\mathbf{s}}, \varepsilon_{v}^{p}, \mathbf{e}^{p}\right)=$ & $\begin{array}{l}\left|K_{m}-\overline{K_{p}}\right| \quad \text { for first loading } \\
\left|\frac{\overline{\mathrm{n}}_{p} \varsigma_{r}}{\eta} K_{m}-\overline{K_{p}}\right| \text { for unloading } \\
\left|\varsigma_{r} K_{m}-\overline{K_{p}}\right| \quad \text { for reloading }\end{array}$ \\
\hline
\end{tabular}




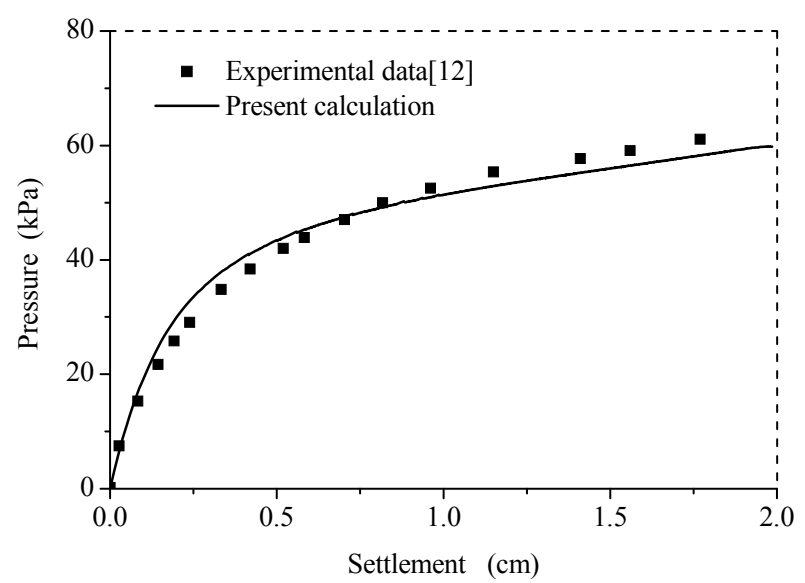

Fig. 3 The load-settlement of the strip foundation under the monotonic loading

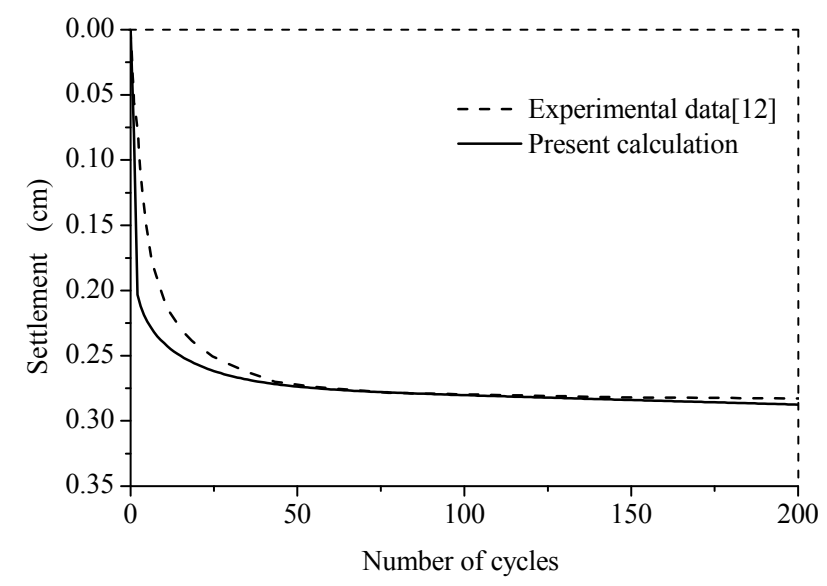

Fig. 4 The settlement accumulation of the strip footing under the cyclic loading

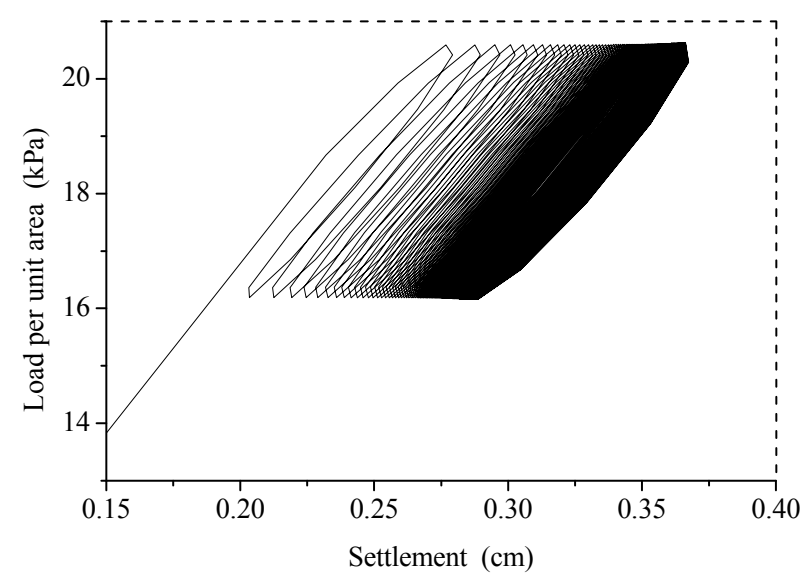

Fig. 5 The calculated cyclic load-settlement curve which are the 8-node biquadratic displacement element and the pore-pressure element CPE8P [11].

The coupled analyses of the monotonic and cyclic pull-out behaviors of VLA were carried out on Itsukaichi marine clay with a uniform shear strength and its weight is neglected. Details about the clay can be seen in $\mathrm{Hu}$ and Liu [4]. Thus, there are one additional boundary condition related with the drainage and two necessary analysis steps should be clarified. The top surface of the soil domain is drained, and others are undrained. Two steps in the present analyses are as follows:

First, in the geostatic step, the soil was hydrostatically consolidated under the pressure of $110 \mathrm{kPa}$ to obtain the clay with a uniform strength of $28 \mathrm{kPa}$.

Second, in the coupled analysis step, for the monotonic pull-out process, the displacement control was used to simulate a rigid plate anchor pull-out continuously until the allowed embedment loss reached; for the cyclic pull-out process, the load control was used and the option of automatic time incrementing in ABAQUS was open to make the solution converging. Moreover, one additional parameter in a coupled analysis is the permeability $k_{p}$ (see Table 2).

\section{RESULTS AND DISCUSSIONS}

\subsection{Monotonic Pull-out Behaviors}

Fig. 6 shows that soil failure mode in the case of $D / B=3.3$ ( $D$ is the embedment depth of the anchor) for the monotonic pull-out analysis. It demonstrates that the soil backflow initiated beneath the anchor. Fig. 7a illustrates the capacity factor-displacement curves of the VLA with different embedment ratios $(D / B=2,3.3,6$ and 8), from which the ultimate pull-out capacity (UPC) of VLA can be determined. In this paper, the $U P C$ is considered as the load beyond which the load-displacement curve becomes linear. This criterion is adopted by Neely et al. [13] and Hanna et al. [14] for plate anchor, Vesic [15] and Das and Shin [12] for shallow foundation, Rao and Prasad [16] for piles. The UPC of VLA with $D / B=3.3$ is $Q_{f}=1004 \mathrm{kN}^{-1}$, which will be taken as a reference to analyze the cyclic pull-out behaviors of VLA. Fig .7b shows the comparison between the current calculation and the analytic solution [17] and experimental data [18]. It demonstrates that the numerical method proposed here can produce a reasonable result.

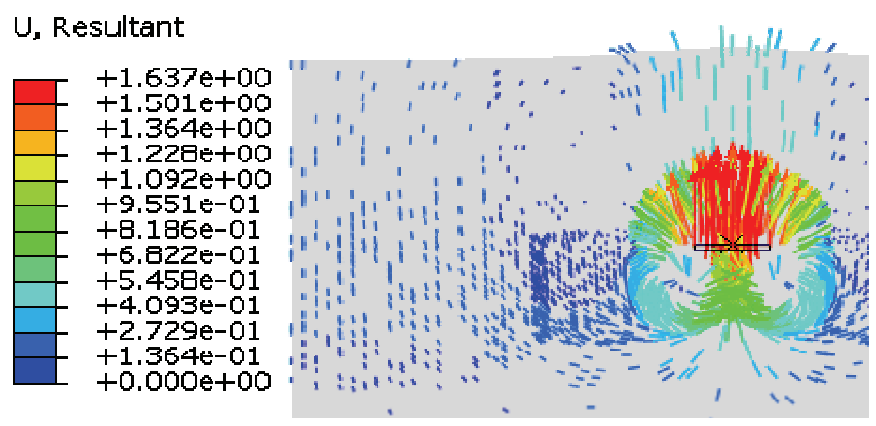

Fig. 6 Soil failure mode in the case of $D / B=3.3$ 
Table 2 Soil and model parameters used in the present simulations

\begin{tabular}{|c|c|c|c|c|c|c|c|c|c|c|}
\hline & $v$ & $e_{0}$ & $\kappa$ & $\lambda$ & $M$ & $\gamma$ & $\zeta_{r}$ & $\eta$ & $\beta$ & $k_{p}$ \\
\hline Saturated clay[12] & 0.3 & 0.929 & 0.05 & 0.17 & 1.5 & 2 & 2 & 100 & 0.001 & $1 \mathrm{e}-6 \mathrm{~m} / \mathrm{s}$ \\
\hline Itsukaichi marine clay[4] & 0.3 & 2.422 & 0.057 & 0.349 & 1.56 & 2 & 5 & 100 & 0.005 & $1 \mathrm{e}-6 \mathrm{~m} / \mathrm{s}$ \\
\hline
\end{tabular}

Table 3 Cyclic loading cases

\begin{tabular}{|c|c|c|c|c|c|c|c|c|c|c|c|c|c|}
\hline Case & 1 & 2 & 3 & 4 & 5 & 6 & 7 & 8 & 9 & 10 & 11 & 12 & 13 \\
\hline$Q_{m} / Q_{f}(\%)$ & \multicolumn{3}{|c|}{20} & \multicolumn{2}{|c|}{45} & \multicolumn{3}{|c|}{35} & \multicolumn{3}{|c|}{42.5} & \multicolumn{2}{|c|}{55} \\
\hline$Q_{c y c} / Q_{f}(\%)$ & 2 & 3.5 & 5 & 40 & 45 & 5 & 10 & 17.5 & 10 & 17.5 & 20 & 17.5 & 30 \\
\hline
\end{tabular}

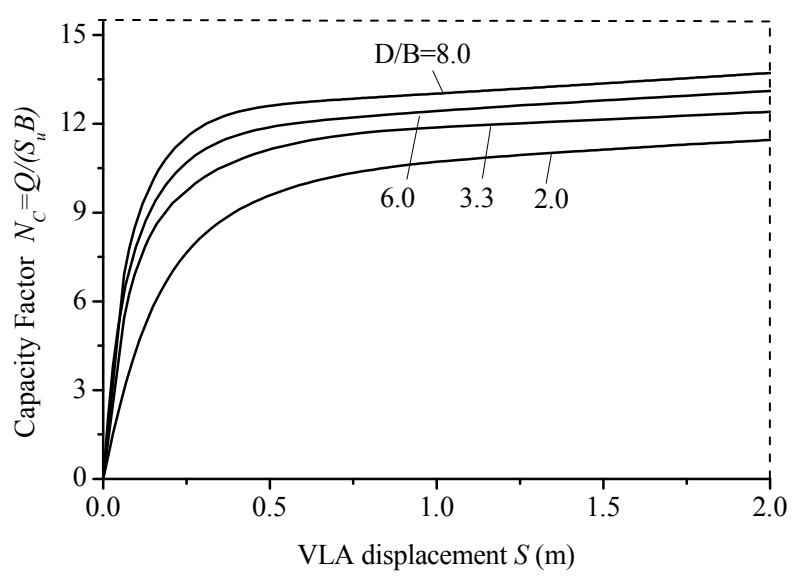

(a)

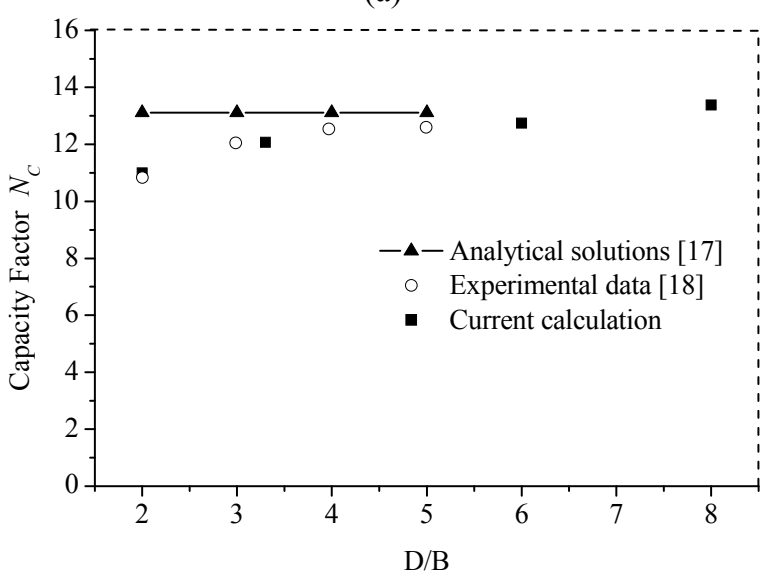

(b)

Fig. 7 Results of the plate anchor with different embedment ratios: (a) Monotonic capacity factor-displacement curves; (b) Comparison between current calculation and previous works

\subsection{Cyclic Pull-out behaviors}

In a taut (or catenary) mooring system the loads transmitted to the anchors though the mooring lines will always be in tension [2]. Accordingly, the cyclic loading pattern applied on VLA in the numerical simulations is shown in Fig. 8, i.e., the VLA is subjected to a mean load $Q_{m}$ and then a superimposed cyclic load $Q_{c y c}$. A series of numerical tests are designed according to different combinations of $Q_{m}$ and $Q_{c y c}$ and listed in Table 3.

\subsubsection{VLA Pull-out Displacement Responses}

Fig. 9 shows that the development of load-displacement hysteresis loops of the coupled system in Case 13 predicted by the numerical method based on the BSP model. It can be seen that different from the static limited equilibrium analysis adopted by DNV, the method can describe the whole cyclic pull-out process of the VLA.

Fig. 10 shows the transient pull-out displacement of VLA with loading cycles. Three types of displacement responses have been obviously obtained, which suggests that under different cyclic loading, three states of VLA can be reached:

(1) The cyclic stable state, in which the rate of the displacement accumulation of VLA in the initial loading cycles is higher and then decreases in the later loading stage until almost to zero (Cases 3 and 6 in Fig. 10, as well as Cases 1,2,7 in Tab. 3);

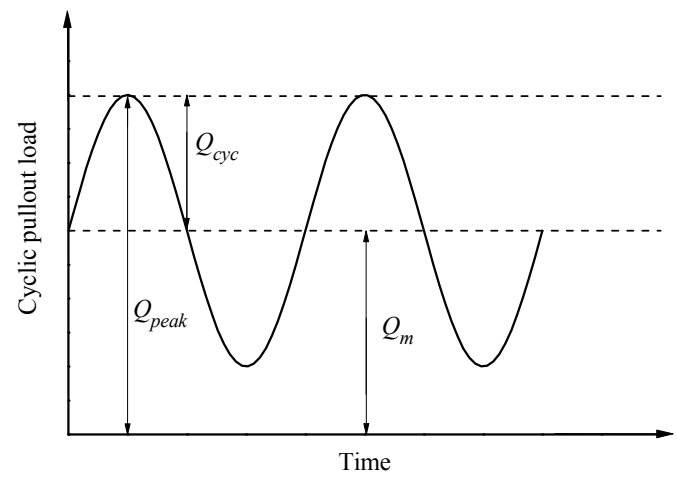

Fig. 8 Cyclic loading pattern 


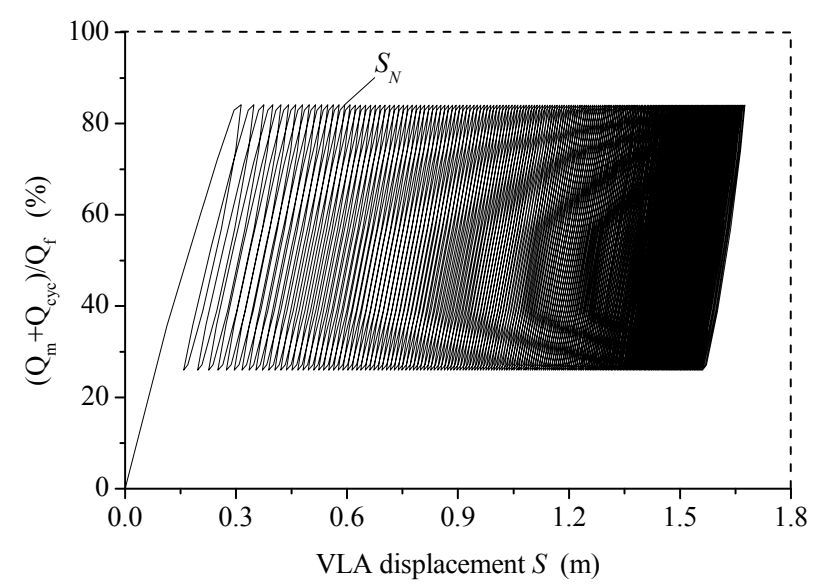

Fig. 9 The development of load-displacement hysteresis loops in Case 13

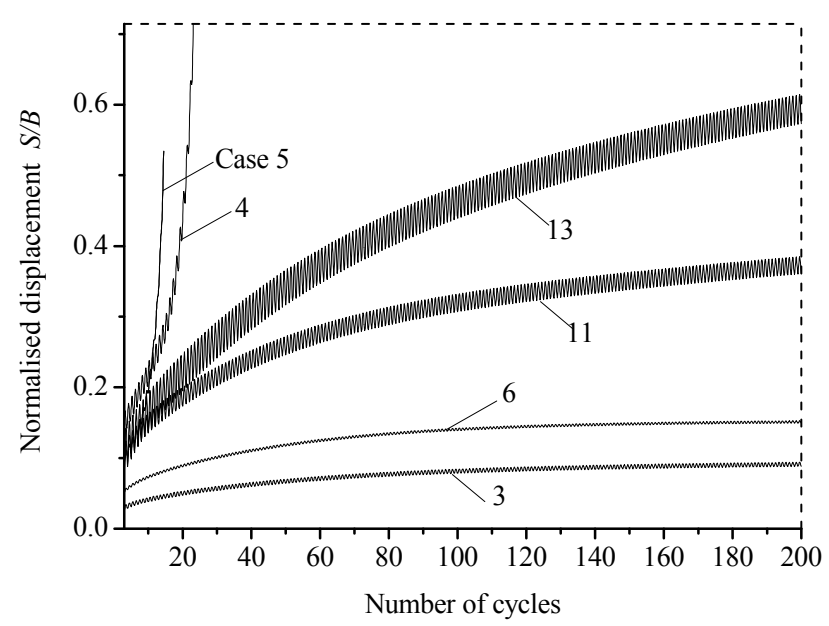

Fig. 10 The transient displacement of VLA with loading cycles

(2) The cyclic hypo-stable state, in which the displacement of VLA increases rapidly in the initial few cycles, but then the rate of the movement decreases to a non-zero stable value (Cases 11 and 13 in Fig. 10, as well as Cases 8-10,12 in Tab. 3);

(3) The cyclic failure state, in which the VLA moves rapidly upwards until reach failure due to large displacement within few loading cycles (Cases 4 and 5).

\subsubsection{Cyclic Stiffness Of The VLA-Soil Coupled System}

In order to investigate the evolvement of stiffness of the VLA-soil coupled system, similar to the definition of the stiffness of the soil, we adopt the following relation to calculate the cyclic stiffness of the coupled system:

$$
G_{S N}=2 Q_{c y c} / S_{N}
$$

where $S_{N}$ denotes the displacement at the top of the $N$ th loaddisplacement hysteresis loop (shown in Fig. 9).

The cyclic stiffness of the coupled system is normalized by $G_{S 1}$ and its evolvement during the whole cyclic loading process is shown in Fig. 11. It demonstrates that for different type of displacement responses, the cyclic stiffness shows different characters. For the stable state, the cyclic stiffness decreases gradually, and reach the stable state within 200 cycles; for the hypo-stable state, the stiffness decreases gradually after 500 cycles; for the failure case, the stiffness decreases steeply within the few cycles.

Besides, it can be found in Fig. 11 that the peak cyclic load $Q_{\text {peak }}$ (the sum of $Q_{m}$ and $Q_{c y c}$ ) has a great influence on the degradation in stiffness, larger $Q_{\text {peak }}$ causes more degradation (comparing Case 4 with 12); and the rate of degradation is directly proportional to $Q_{c y c}$ (comparing Case 4 with 5) and inversely proportional to $Q_{m}$ (comparing Case 8 with 12).

\section{CONCLUSIONS}

A numerical method based on the bounding surface plasticity (BSP) model for assessing the cyclic pull-out behaviors of the embedded plate anchor is presented in this paper. A series of cyclic pull-out tests under different cyclic loading levels as well as the monotonic test were simulated and analyzed. The following conclusions are drawn based on the results:

(1) The numerical method based on the bounding surface plasticity model can be used for simulating the bearing and pull-out processes of the foundations under both the monotonic and cyclic loading.

(2) The pull-out behaviors of the embedded plate anchor under the different cyclic loading levels show three typical characteristics, i.e., the cyclic stable, the cyclic hypo-stable and the cyclic degradation.

(3) The rate of the degradation in the stiffness of the coupled anchor-soil system increases with the amplitude of the cyclic load but decreases with the mean load.

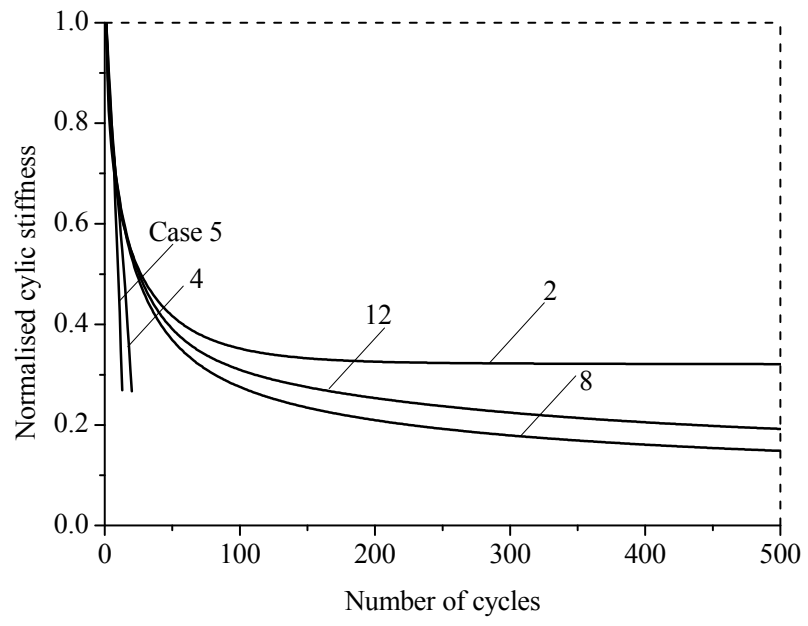

Fig. 11 The evolvement of normalized cyclic stiffness of the coupled system

\section{ACKNOWLEDGEMENTS}


Financial support from the National Natural Science Foundation of China (Grant no. 51309213) and the 973 program of China (Grant no. 2014CB046200) is gratefully acknowledged.

\section{REFERENCES}

[1] Anderson KH. Bearing capacity under cyclic loadingoffshore, along the coast, and on land. Canadian Geotechnical Journal, 2009, 46: 513-535.

[2] Det Norshke Veritas. Design and installation of fluke anchors in clay. DNV RP-E302. 2002.

[3] Wong P, Gaudin C, Randolph MF, Cassidy MJ, Tian Y. Performance of suction embedded plate anchors in permaent mooring application. Proceedings of the $22^{\text {nd }}$ International Offshore and Polar Engineering Conference, Rhodes, 2012: 640-645.

[4] $\mathrm{Hu} \mathrm{C}$, Liu HX. Implicit and explicit integration schemes in the anisotropic bounding surface plasticity model for cyclic behaviors of saturated clay. Computers and Geotechnics, 2014, 55: 27-41.

[5] Andersen KH, Lauritzsen R. Bearing capacity for foundations with cyclic loads. Journal of Geotechnical Engineering, ASCE, 1988, 114(5): 540-555.

[6] Ponniah DA, Finlay TW. Cyclic behavior of plate anchor. Canadian Geotechnical Journal, 1988, 25: 374-381.

[7] Datta MSK, Gulhati G, Achari. Behavior of plate anchors in soft cohesive soils under cyclic loading. Indian Geotechnical Journal, 1990, 20(23): 206-224.

[8] Singh SP, Ramaswamy SV. Response of plate anchors to sustained-cyclic loading. Indian Geotechnical Journal, 2002, 32(32): 161-172.

[9] Singh SP, Ramaswamy SV. Influence of frequency on the behaviour of plate anchors subjected to cyclic loading. Marine Georesources and Geotechnology, 2008, 26: 36-50.

[10] Hu C, Liu HX, Huang W. Anisotropic bounding-surface plasticity model for the cyclic shakedown and degradation of saturated clay. Computers and Geotechnics, 2012, 44:34-47.

[11] Hibbit, Karlsson, Sorensen, Inc (HKS). ABAQUS users' manual, version 6.7.1, 2009.

[12] Das BM, Shin EC. Laboratory model tests for cyclic loadinduced settlement of a strip foundation on a clayey soil. Geotechnical and Geological Engineering, 1996, 4: 213225.

[13] Neely WJ, Stuart JG, Graham J. Failure loads of vertical anchor plates in sand. Journal of the Soil Mechanics and Foundations Division, ASCE, 1973, 99(9): 669-685.

[14] Hanna AM, Ranjan G. Pullout-displacement of shallow vertical anchor plates. Indian Geotechnical Journal, 1992, 22(1): 55-62.

[15] Vesic AS. Analysis of ultimate loads on shallow foundations. Journal of the Soil Mechanics and Foundations Division, ASCE, 1973, 99: 45-73.

[16] Rao SN, Prasad YVSN. Uplift behavior of pile anchors subjected to lateral cyclic loading. Journal of Geotechnical Engineering, 1993, 119(4): 786-790.

[17] Martin CM, Randolph MF. Applications of the lower and upper bound theorems of plasticity to collapse of circular foundations. Proceedings of the 10th International. Conference of the International Association for Computer Methods and Advances in Geomechanics, 2001, 2: 14171428.

[18] Das BM, Shin EC, Dass RN, Omar MT. Suction force below plate anchors in soft clay. Marine Georesources and Geotechnology, 1994, 12(1): 71-81. 